\title{
Vermicompost- A Suitable Medium for Delivering Consortium of Bio Inoculants into the Rhizosphere of Black Pepper
}

\section{Suseela Bhai R*, Lamya Moideen, Sangeeth KP and Sreeja K}

ICAR- Indian Institute of Spices Research, Calicut, India

*Corresponding Author: Suseela Bhai R, ICAR- Indian Institute of Spices Research, Calicut, India.

Received: August 23, 2019; Published: September 20, 2019

DOI: $10.31080 /$ ASAG.2019.03.0655

\begin{abstract}
Vermicompost amended with suitable combinations of biocontrol agents and biofertilizer organisms were tested for their effect on plant growth and disease suppression in black pepper in planta. The biocontrol agents viz. P. aeruginosa (MTCC 5178 and MTCC5411), Curtobacterium luteum (strain TC 10) an endophytic bacteria, T. harzianum (MTCC5179), P. chlamydosporia (MTCC5412) and strain of biofertilizer organisms viz. Azospirillum sp. ( $\mathrm{N}_{2}$ fixer), P. fluorescens (P-solubilizers) and Paenibacillus glucanolyticus (Potash mobilizer) were used in the study. These strains have been individually proved as efficient in disease suppression and growth promotion in black pepper. Since these organisms are applied almost at the same time for different functions such as Phytophthora and nematode suppression, growth promotion etc, it is intended to develop a consortium holding all the potential organisms together in a common base media so that all of them can be introduced into the rhizosphere environment in a single application, that not only save time but also economical by way of reducing the cost of application. Vermicompost was selected as the base medium and the organisms having specific functions were individually tested for their growth and proliferation in vermicompost both under sterile and non - sterile conditions. The result showed that both non-sterile and sterile vermicompost supported the growth of all the targeted organisms except Pochonia chlamydosporia that showed a negative trend. When this bio - amended vermicompost medium was applied to the plant base and challenged with Phytopthora capsici, the consortium holding P aeruginosa (strain IISR 853) + T. harzianum + biofertilizer showed comparatively significant growth when compared to all other combinations. However, the lowest disease incidence (5.6\%) was observed with P aeruginosa (strain IISR 6) + biofertilizer organisms. Since P aeruginosa (strain IISR 853) + T. harzianum + biofertilizer showed increased growth and at par with the best combination for disease suppression, it is possible to use this consortium also for the better growth and disease suppression in black pepper.

Keywords: Biocontrol; Bioconsortia; Biofertilizer; Bio Inoculants; Black Pepper; Foot Rot Disease; Vermicompost
\end{abstract}

\section{Introduction}

Crop losses due to foot rot caused by Phytophthora capsici is recognized as one of the major causes for the low productivity of black pepper in India. The pathogen infects all parts of the vine and expression of symptoms depends on the site of infection. It is a soil borne oomycete and thrives in soil and in infected plant debris all throughout the year. But the detectability was maximum during the wet period. The root infection caused by plant parasitic nematodes, viz. Radopholus similis and Meloidogyne incognita and P. capsici either alone or in combination leads to slow decline resulting in decreased vigour and productivity leading to gradual death of the vine [1]. Integrated disease management involving chemical, cultural and biological methods, besides host resistance is the ideal strategy to combat the disease [2]. Though chemical control by systemic/contact fungicides can be adopted as a prophylactic measure [3], it is undesirable as they pollute the environment and residues left in the product are hazardous to human health. Alternative approaches being biological agents, currently known to have efficacy against Phytophthora, may offer better possibilities for long term control than using chemicals alone. Hence for the integrated management of foot rot and slow decline disease of black pepper, biocontrol agents viz. Tharzianum, Pseudomonas fluorescens, P.chlamydosporia etc. are being used. They are being multiplied and formulated with carrier media such as coffee husk, farm yard manure, sorghum grains, talc etc. and applied at the plant basins along with chemicals in an integrated manner [4,5]. Simultaneously biofertilizer organisms viz. Azospirillum, Azotobacter, phosphobacteria etc. are used for growth improvement mostly in integrated nutrient management systems. Besides, vermicompost is also being used as an organic amendment for nutrient management as it contains adequate quantities of N, P, K and several micronutrients essential for plant growth and varying type of enzymes, which can promote the growth of the beneficial organisms. Since all these amendments including bioagents and biofertilizers are applied almost at the same time for Phytophthora and nematode suppression as well as for plant growth promotion, it is intended to develop a consortium holding all the potential organisms together in a common base media such as FYM or vermicompost so that a single application can be made possible to introduce all the potential organisms into the rhizosphere environment that not only saves time but also economical by way of reducing the cost of cul- 
tivation. However, no attempt has been made so far to explore the possibility of combining all these biocontrol agents and biofertilizer in a common base. If vermicompost is able to support the growth and proliferation of both biocontrol agents and biofertilizer, it is possible to develop an eco - friendly package to enhance the plant growth and suppression of pathogen viz. Phytophthora capsici, Radopholus similis and Meloidogyne incognita. Therefore, in this study an attempt was made to explore the cultivable micro flora associated with vermicompost and its biocontrol potential and also to evaluate the efficacy of vermicompost for supporting the growth of biocontrol agents and biofertilizer organisms in improving the growth and disease suppression in black pepper for developing a nutrient supplement package.

\section{Materials and Methods}

The study was conducted in three steps. Initially the associated micro flora and physico - chemical properties of vermicompost was studied in comparison with FYM and evaluated the biocontrol efficacy of the vermicompost associated microflora against $P$ capsici. Secondly the potential biocontrol agents and biofertilizer organisms (given below) were inoculated in sterile and non sterile vermicompost and studied their proliferation at different intervals from $5^{\text {th }}-20^{\text {th }}$ day. Finally vermicompost amended with bio consortia was supplemented to the plant base in different combinations and studied their effect on growth promotion and suppression of Phytophthora by challenging.

\section{Studies on the associated culturable microflora of} vermicompost

Microflora of vermicompost and farm yard manure was studied using different media using dilution plate method for enumeration of specific organisms like Pseudomonas sp. Actinomycetes, Potash mobilizers, Phosphorus solubilizers, Nitrogen fixers and Trichoderma species. The media used were Nutrient agar for total bacteria, Potato dextrose agar for total fungi, King's B media for Pseudomonas, Actinomycetes isolation agar for Actinomycetes, Sucrose minimal salt media (SMSM) for Potash mobilizers, Nitrogen free bromothymol media (NFB) for Azosprillum sp, Nitrogen free mallic acid media (NFG) for Azotobacter, Pikovskaya medium for Phosphate solubilizers and Trichoderma specific media for Trichoderma. The organisms grown in each media were enumerated and calculated as cfu/g

\section{Antagonistic potential of organisms isolated from vermicompost}

The isolated bacterial and Actinomycetes cultures were tested for inhibitory effect on P. capsici. The cultures were streaked on either side of the P. capsici (5mm mycelial plugs) placed at the center of $90 \mathrm{~mm}$ petri dishes containing PDA. Inoculated plates were incubated at room temperature for 72 - 120 and the radial growth was measured and compared with control where $P$. capsici alone was inoculated. the percentage inhibition was calculated as

$\mathrm{PI}=\frac{\mathrm{C}-\mathrm{T}}{\mathrm{C}} \mathrm{X} 100$
Where, $\mathrm{PI}=$ Percentage inhibition, $\mathrm{C}=$ Radial growth of the pathogen in control plate $(\mathrm{mm}) \mathrm{T}=$ Radial growth of the pathogen in Dual culture (mm)

Study on the proliferation of biocontrol agents and bio-fertilizers in vermicompost

Bio - control and bio - fertilizer organisms used in the study were maintained in the bio control repository at ICAR _ IISR, Kozhikode. Biocontrol agents used were Pseudomonas aeruginosa, Curtobacterium luteum, Trichoderma harzianum and Pochonia chlamydosporia and Biofertilizer organisms used were Azospirillum sp. (N2 fixer), P. fluorescens (P-solubilizer) and Paenibacillus glucanolyticus (Potash mobilizer).

The biocontrol agents and biofertilizer organisms mentioned above were sub cultured and made into pure form in respective media as mentioned elsewhere. Vermicompost made from FYM and plant residues was packed in polythene bags @ $1 \mathrm{~kg} / \mathrm{bag}$ in required numbers and made into two sets. One set was sterilized by autoclaving at $121^{\circ} \mathrm{C}$ for $1 \mathrm{~h}$ and the other set was kept unsterilized. There were six treatments and two replications for each treatment. Both sterilized and non - sterilized vermicompost were inoculated with $100 \mathrm{ml}$ culture (cfu/ml given in Table 1) of the biocontrol agents and biofertilizer organisms and thoroughly mixed and incubated at $25-27^{\circ} \mathrm{C}$ for $>20$ days. The initial spore load was enumerated by dilution pour - plate method described by Kale., et al. (1992) using respective media as mentioned elsewhere. The incubated treatments were sampled at 5, 10 and 20 days interval and estimated the population of each organism as above. P. aeruginosa ( strains IISR 6 and IISR 853) were enumerated using Kings B medium (King., et al. 1954), Phosphate solubilizers $P$. fluorescens in Pikovskaya's Medium, Pikovsakya (1948), Azospirillum sp. in N2 free bromothymol blue amended with Kanamycin $(0.2 \mu \mathrm{l} / 100 \mathrm{ml} @$ $5 \mathrm{omg} / \mathrm{ml}$ water conc.), P. glucanolyticus in Sucrose minimal salt medium amended with Gentamycin $(4 \mu \mathrm{l} / 100 \mathrm{ml} @ 34 \mathrm{mg} / \mathrm{ml}$ methanol Conc.), C. luteum in Nutrient agar amended with polymyxin $\mathrm{B}(20 \mu \mathrm{l} / \mathrm{ml})$, P. chlamydosporia using Potato Dextrose Agar and T, harzianum in Trichoderma specific medium.

Study on the effect of bioconsortia in vermicompost towards plant growth and disease suppression in planta

The experiment was designed in CRD with 14 treatments, 6 replications and 3 plants per replication. Single node rooted cuttings of black pepper was used for the experiment. Potting mixture was prepared in 1:1:1 ratio using soil, sand and farmyard manure and filled in earthenware pots of size $12 \mathrm{x} 12$ ". These pots were planted with rooted cuttings and maintained by irrigating on alternate days.

\section{Preparation of bioconsortia}

Vermicompost @ 1 kg without sterilization was taken in polythene bags and inoculated with $100 \mathrm{ml}$ of individual culture having $\log 8 \mathrm{cfu} \mathrm{ml}^{-1}$ of the biocontrol agents and biofertilizer organisms as 


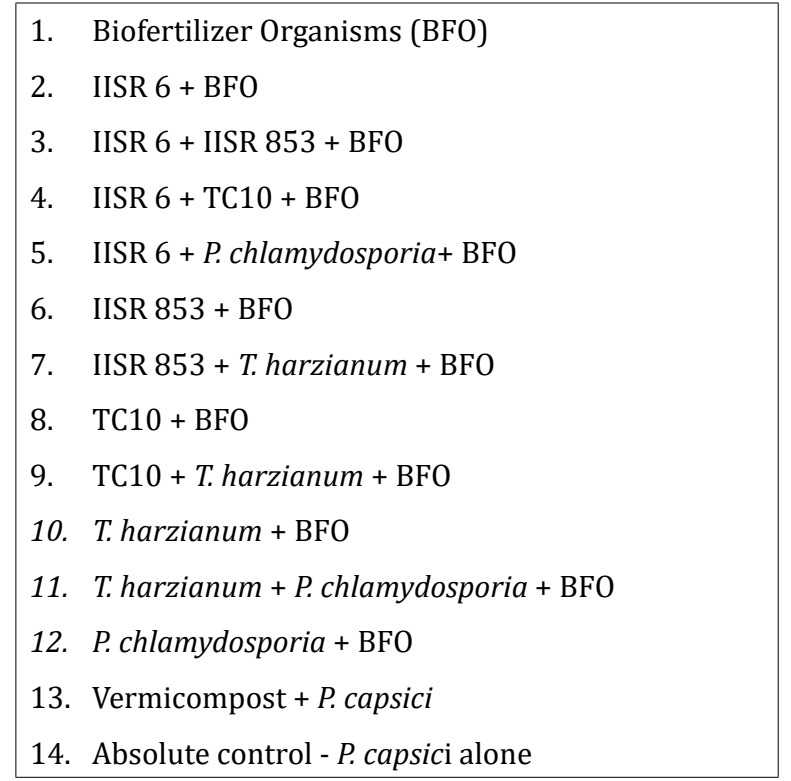

Table 1: Treatment details.

given elsewhere and was mixed thoroughly. This was incubated at room temperature for 6 days. After six days these were made into different bio consortia combinations my mixing together in equal proportions for different treatments (Table 1).

After establishment of the plants, different treatments were given as specified as in Table $1 @ 100 \mathrm{~g} /$ pot and repeated the treatment after 30 days. The plant growth parameters like height of the plant and no. of leaves were recorded before application. After $11 / 2$ months, the plants were challenged with P. capsici and observed for disease incidence at regular intervals and calculated the plant growth and disease incidence after six months. The data was analysed using Window stat statistical package.

\section{Results}

Physicochemical properties of the VC used in comparison with FYM

Nutrient status of the VC and FYM is shown in Table 2. Both vermicompost and FYM fall above neutral $\mathrm{pH}$ which shows that they are not acidic. The moisture content of VC is around 59\%. N, P, Ca and $\mathrm{Mg}$ content were almost equivalent to FYM but $\mathrm{K}$ content is more than double of FYM.

\begin{tabular}{|l|c|c|}
\hline $\begin{array}{c}\text { Physicochemical } \\
\text { Properties }\end{array}$ & Vermicompost (used) & $\begin{array}{c}\text { Farmyard } \\
\text { Manure }\end{array}$ \\
\hline $\mathrm{pH}$ & 7.32 & 7.93 \\
\hline $\begin{array}{l}\text { Moisture Content } \\
(\%)\end{array}$ & 59.18 & 13.63 \\
\hline $\mathrm{N}_{2}(\%)$ & 1.54 & 1.708 \\
\hline $\mathrm{P}(\%)$ & 0.3 & 0.4 \\
\hline $\mathrm{K}(\%)$ & 1.48 & 0.61 \\
\hline $\mathrm{Mg}(\%)$ & 0.19 & 0.29 \\
\hline $\mathrm{Ca}(\%)$ & 1.26 & 1.235 \\
\hline
\end{tabular}

Table 2: Physicochemical properties of VC.
Culturable microflora associated in vermicompost in comparison with farm yard manure

The micro flora associated with vermicompost was studied in comparison with farm yard manure using different media for enumeration of specific organisms viz. Pseudomonas sp, Actinomycetes, Potash mobilizers, Phosphorus solubilizers, Nitrogen fixers and Trichoderma species. The result showed that there is no significant difference between VC and FYM in total culturable microbial load when compared to potting mixture (Figure 1).
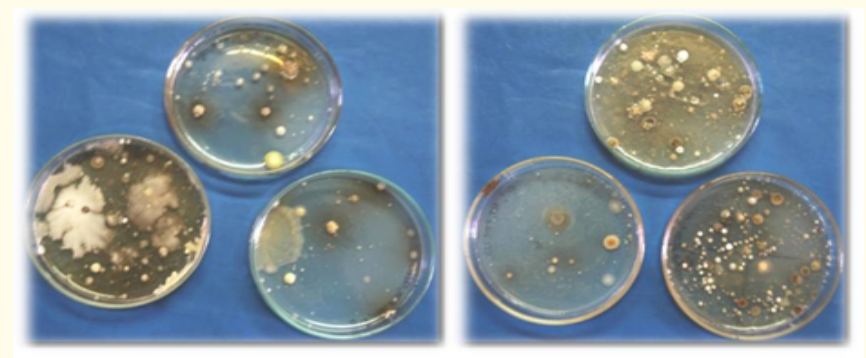

Figure 1: Micro organisms isolated from A)VC B) FYM.

The total culturable microbial load of vermicompost (5.04 log $\mathrm{cfu} / \mathrm{g}$ ). was found at par with FYM (5.24 log cfu/g). Azotobacter and Azospirillum populations (N2 fixers) were found higher in vermicompost, where as Potash mobilisers, Actinomycetes and phosphate solubilizers were found higher in farmyard manure. Trichoderma spp. were not found in both the amendments used (Figure 2).

Antagonistic potential of microbes isolated from vermicompost

From vermicompost 15 distinct microbial colonies were isolated of which three were bacteria of bacillus type, five were actinomycetes, three were fluorescent pseudomonas and one each of $\mathrm{Az}$ spirillum Acetobacter and $\mathrm{P}$ solubizer respectively from Nitrogen free bromothymol media (NFB), Nitrogen free maleic acid media (NFG) and Pikovaskay's medium. The 15 microbial colonies isolated were designated as VC1 - VC15. Among the 15 isolates, four isolates (Vc 1, Vc 11, Vc14 and Vc15,) showed > 50\% inhibition (Table 4) of which two isolates viz. Vc1 and Vc 11 showed $>70 \%$ inhibition. The isolates Vc1 and Vc11 belonged to Pseudomonas and Actinomycete group respectively. All the other isolates showed less than $40 \%$ inhibition (Figure2, Figure3) The isolate Vc 10 showed the minimum inhibition (3.07\%) against $P$. capsici. The fungal isolates obtained were all slow growing types and so they were not tested for antagonism against $P$. capsici. (Figure.4).

Study on the proliferation of biocontrol agents in vermicompost

The growth and multiplication of promising biocontrol agents that have been in use for controlling foot rot disease of black pepper, were studied using sterile and non-sterile vermicompost at 


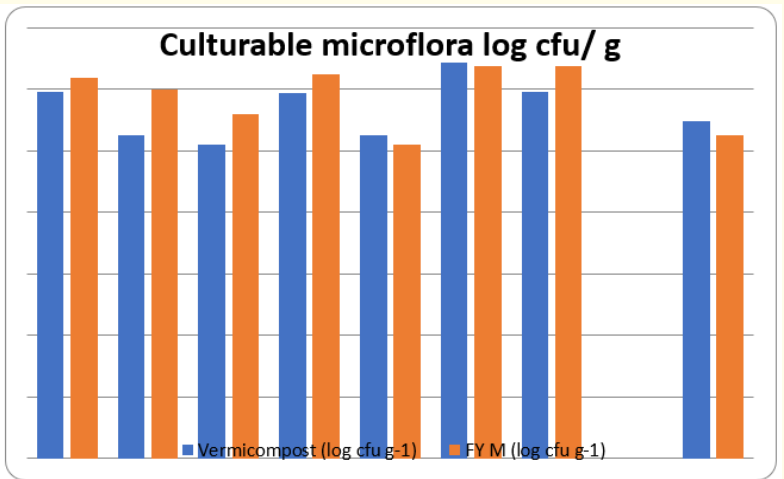

Figure 2: Culturable Microflora associated with VC in comparison with FYM (log cfu/g).

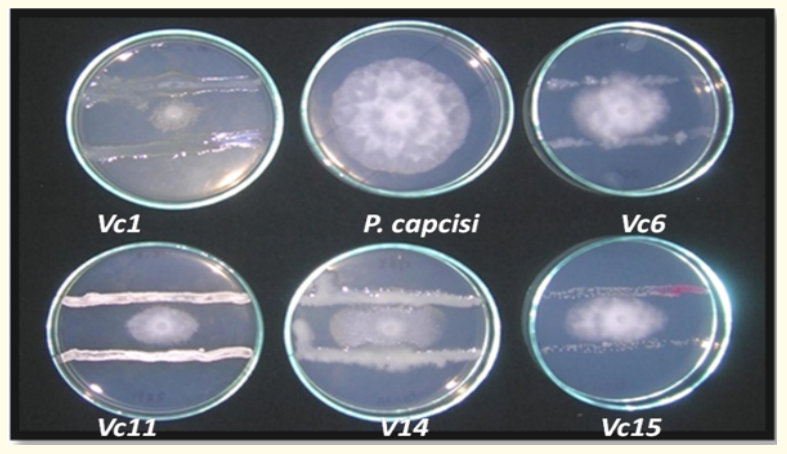

Figure 3: Antagonistic effect of VC isolates with $>50 \%$ inhibition against $P$. capsici (VC 11-Actinomycte Act 9).

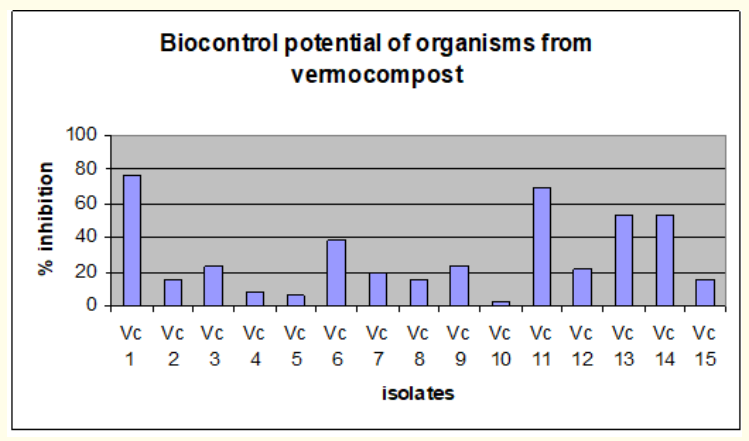

Figure 4: Inhibitory effect of Biocontrol and biofertilizer organism against $P$. capsica.

different intervals from $5^{\text {th }}-20^{\text {th }}$ day after inoculation. The initial inoculum load in the form of cfu at the time of inoculation was estimated and compared with cfu obtained at different intervals (Figure 5).

Among the biocontrol agents, P. aeruginosa, T. harzianum and Azospirillum showed comparative increase in population under non - sterile conditions of which P. aeruginosa strain IISR 853 showed the highest increase (8.68\%) followed by P. aeruginosa strain IISR $6(2.98 \%)$ in 20 days time. Though T. harzianum showed an initial

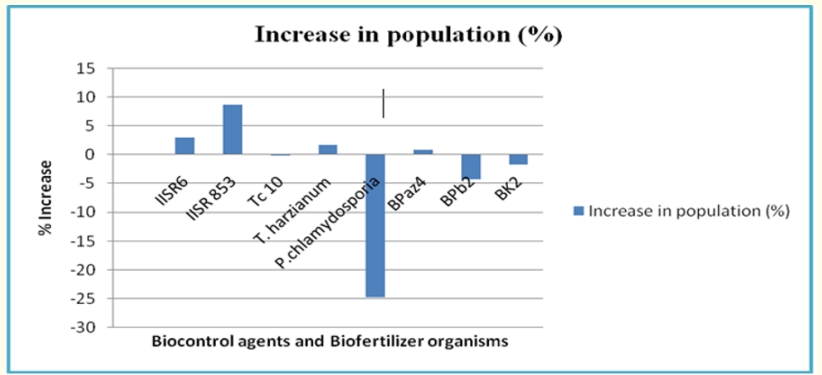

Figure 5: Difference in proliferation efficiency of $\mathrm{BC} / \mathrm{BF}$ organisms in non-sterile VC.

increase in population after 5 days, a decrease was noted after 10 and 20 days resulting in a final increase of only $1.72 \%$. Azospirillum sp. showed an increase of only $0.82 \%$. Phosphate solubilizers and Potash mobilizer showed decrease in the population after 5 days but increased gradually after 10 and 20 days showing an overall decrease in population of $4.25 \%$ and $1.73 \%$ respectively. C. luteum almost maintained its population even after 20 days with only slight decrease $0.23 \%$ from the initial inoculum. The highest decline in population was observed with $P$. chlamydosporia $(24.79 \%)$ showing its limited ability to proliferate in non sterile vermicompost (Table 3).

In sterile vermicompost, all the isolates except Phosphate solubilizers, Potash mobilizer and P. chlamydosporia showed increase in population. P. aeruginosa strain IISR 853 showed highest proliferation of $9.06 \%$ followed by . harzianum (6.05\%). A sudden decline followed by a gradual increase resulting in an overall population reduction of $16.73 \%$ was found with $P$. chlamydosporia in sterile vermicompost and it is less than that obtained in non-sterile vermicompost A comparative study of the two conditions viz. sterile and non - sterile vermicompost on the proliferation of the biocontrol agents showed that sterile vermicompost is more effective for the proliferation of biocontrol agents targeted. The major difference was observed with T. harzianum (245.7\%) and Azospirillum sp (200\%) when compared with non sterile vermicompost. All the other isolates also showed increase in population after 5, 10 and 20 days in sterile vermicompost. Though $P$. chlamydosporia showed decline in population in both sterile and non sterile vermicompost, the decline was comparatively less in sterile VC when compared to non-sterile VC (Table 3, Figure 6).

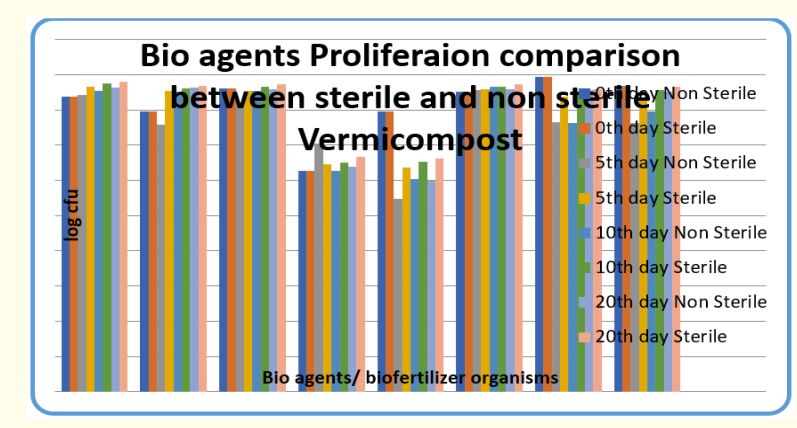

Figure 6: Comparative po5. Study on the effect of combinations of biocontrol agents in vermicompost on plant growth. 
When vermicompost was amended with biocontrol agents and biofertilizer organisms in different combinations and applied to the plants, the consortium containing IISR $853+$ T. harzianum + biofertilizer organisms showed better growth of the plants (Table 4). An increase in growth of $172.57 \%$ in six months was obtained for this treatment when compared to initial growth whereas the other treatments showed and increase ranging from $12.59-65.57 \%$ only (Table 4). When the plants were challenged with P. capsici infection ranged from $5.56-61.12 \%$. The lowest infection of 5.56 was observed with IISR 6 + Biofertilizer organisms followed by IISR 6 + P. chlamydosporia + Biofertilizer, IISR 853 + NPK Organisms, IISR $853+$ T. harzianum + Biofertilizer, T. harzianum + Biofertilizer, $T$. harzianum $+P$. chlamydosporia + Biofertilizer. The highest disease incidence was observed in treatments viz, T3, T9, T12, T13 and T14. The results very clearly showed that the bio consortium containing IISR 6 + Biofertilizer organisms are effective in controlling the disease incidence and IISR $853+T$. harzianum + biofertilizer organisms are effective in improving the plant growth (Table 4, Figure 7-8).

\begin{tabular}{|c|c|c|c|c|}
\hline \multirow[t]{2}{*}{ SL. No } & \multirow[t]{2}{*}{ Treatments } & \multicolumn{2}{|c|}{$\begin{array}{l}\text { Plant growth } \\
\text { (cm) }\end{array}$} & \multirow{2}{*}{$\begin{array}{c}\% \\
\text { increase }\end{array}$} \\
\hline & & Initial & Final & \\
\hline $\mathrm{T} 1$ & NPK Organisms & 18.578 & 23.030 & 23.96 \\
\hline $\mathrm{T} 2$ & IISR 6 + NPK Organisms & 22.223 & 25.022 & 12.59 \\
\hline T3 & $\begin{array}{l}\text { IISR } 6+\text { IISR } 853+\mathrm{NPK} \\
\text { Organisms }\end{array}$ & 21.000 & 25.013 & 19.11 \\
\hline $\mathrm{T} 4$ & $\begin{array}{l}\text { IISR } 6+\mathrm{TC} 10+\mathrm{NPK} \\
\text { Organisms }\end{array}$ & 23.428 & 34.500 & 47.26 \\
\hline T5 & $\begin{array}{l}\text { IISR } 6+\text { P.chlamydospo- } \\
\text { ria+ NPK Organisms }\end{array}$ & 19.840 & 28.555 & 43.92 \\
\hline T6 & $\begin{array}{l}\text { IISR } 853+\text { NPK } \\
\text { Organisms }\end{array}$ & 28.062 & 36.195 & 28.98 \\
\hline $\mathrm{T} 7$ & $\begin{array}{l}\text { IISR } 853+T \text {. harzianum + } \\
\text { NPK Organisms }\end{array}$ & 32.305 & 88.055 & 172.57 \\
\hline T8 & TC10 + NPK Organisms & 21.135 & 30.943 & 46.41 \\
\hline T9 & $\begin{array}{l}\mathrm{TC10}+T . \text { harzianum }+ \\
\text { NPK Organisms }\end{array}$ & 26.160 & 39.540 & 51.15 \\
\hline $\mathrm{T} 10$ & $\begin{array}{l}\text { T. harzianum + NPK Or- } \\
\text { ganisms }\end{array}$ & 25.200 & 34.250 & 35.91 \\
\hline $\mathrm{T} 11$ & $\begin{array}{l}\text { T. harzianum }+ \\
\text { P.chlamydosporia }+ \text { NPK } \\
\text { Organisms }\end{array}$ & 22.972 & 32.643 & 42.10 \\
\hline $\mathrm{T} 12$ & $\begin{array}{l}\text { P. chlamydosporia }+\mathrm{NPK} \\
\text { Organisms }\end{array}$ & 24.527 & 40.610 & 65.57 \\
\hline $\mathrm{T} 13$ & Control (Vermicompost) & 26.305 & 8.513 & -10.61 \\
\hline \multirow[t]{2}{*}{$\mathrm{T} 14$} & Absolute control & 31.053 & 48.483 & 56.13 \\
\hline & LSD 5\% & 7.102 & 23.775 & \\
\hline
\end{tabular}

Table 4: Effect of combinations of organisms in VC on growth promotion.

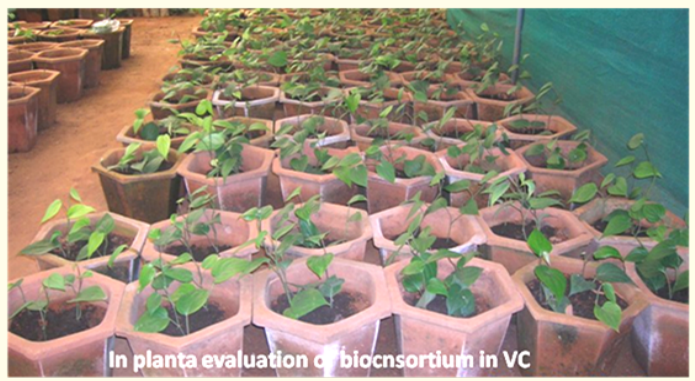

Figure 7: In planta evaluation of bio consortium amended in VC.
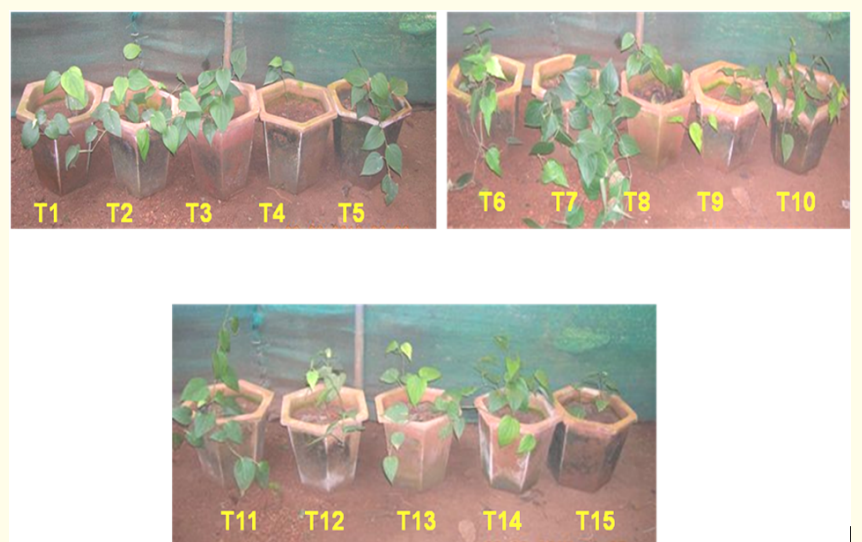

Figure 8: Growth of plants in various bioconsortia.

\begin{tabular}{|l|l|c|}
\hline \multicolumn{1}{|c|}{ Treatment } & $\begin{array}{c}\text { Phytophthora } \\
\text { infection \% }\end{array}$ \\
\hline T1 & Biofertilizer & $45.000(50.00)$ \\
\hline T2 & IISR 6 + Biofertilizer & $7.23(5.56)$ \\
\hline T3 & IISR 6 + IISR 853 + Biofertilizer & $53.85(61.12)$ \\
\hline T4 & IISR 6 + TC10 + Biofertilizer & $33.79(38.89)$ \\
\hline T5 & $\begin{array}{l}\text { IISR 6 + P.chlamydosporia+ Biofertil- } \\
\text { izer }\end{array}$ & $21.69(22.22)$ \\
\hline T6 & IISR 853 + NPK Organisms & $12.83(11.11)$ \\
\hline T7 & IISR 853 + T. harzianum + Biofertilizer & $16.08(16.67)$ \\
\hline T8 & TC10 + NPK Organisms & $27.29(27.78)$ \\
\hline T9 & TC10 + T. harzianum + Biofertilizer & $41.75(44.44)$ \\
\hline T10 & T. harzianum + Biofertilizer & $27.29(27.78)$ \\
\hline T11 & $\begin{array}{l}\text { T. harzianum + P.chlamydosporia + } \\
\text { Biofertilizer }\end{array}$ & $27.29(27.78)$ \\
\hline T12 & P. chlamydosporia + Biofertilizer & $45.00(50.00)$ \\
\hline T13 & Control (Vermicompost alone) & $41.75(44.44)$ \\
\hline T14 & Absolute control (Potting mixture) & $48.25(55.56)$ \\
\hline & Overall mean & $32.72(35.19)$ \\
\hline & CD 5\% & 29.12 \\
\hline & & \\
\hline
\end{tabular}

Table 5: Effect of vermicompost amended bio consortia on Phytophthora infection.

Arcsine transformation (Figures in brackets are original values). 


\section{Discussion}

In the present study, the suitability of vermicompost was tested in the first instance for the proliferation of promising biocontrol agents viz. P. aeruginosa (strain IISR 6, IISR 853), C. luteum (TC 10), T. harzianum, P. chlamydosporia and biofertilizer organism's viz. Azospirillum sp. ( $\mathrm{N}_{2}$ fixer), P. fluorescens (P - solubilizers) and potash mobilizer. These strains have been individually proved as efficient in disease suppression and growth promotion of black pepper at Indian Institute of Spices Research, Kozhikode.

In the present study, the media selected is vermicompost which is almost equal in status to FYM, having similar organic $\mathrm{N}, \mathrm{P}, \mathrm{Mg}$ and Ca content, but with higher $\mathrm{K}$ content, which is more than double of FYM. Similarly the total microbial load was also found to be at par with FYM with Azotobacter and Azospirillum populations (N2 fixers) on the higher side. But it is found that P. chlamydosporia is not proliferating in $\mathrm{VC}$ up to the level of other biocontrol agents. This is supported by Kerry [6] that $P$. chlamydosporia can colonize the rhizosphere of healthy plants, but colonization of soil organic matter is limited.

By artificial inoculation with Azosprillum and Pseudomonas fluorescens, the population was found multiplied at a higher rate rather than any other organisms which indicated the suitability of vermicompost as a carrier media for these organisms. This is supported by the work done by Kumar and Singh [7]. They assessed the effect of inoculation of vermicompost with nitrogen - fixing Azotobacter chroococcum strains, Azosprillum lipoferum and the phosphate solubilizing Pseudomonas striata on N and P contents of the vermicompost and found that the inoculation of $\mathrm{N}_{2}$ fixing bacteria into vermicompost increased the contents of $\mathrm{N}$ and P. So enriching vermicompost with N2 fixers and phosphate solubilizers are advantageous to be a more nutritious media for the better growth of the plant. Similarly enriching VC with T. harzianum and $P$. aeruginosa strains help in reducing the infection by soil borne pathogens especially $P$. capsici and plant parasitic nematodes like $R$. similis. They are also found multiplying in VC showing its ability to hold these organisms. However, presence of Trichoderma species is not found associated with VC originally.

Our results are in concurrence with the reports already available for many crops. According to Chen., et al. [8], selection of VC as organic amendment in soil is recognized as one of the effective methods in the management of soil - borne phytopathogens by changing the soil and rhizosphere environment. It adversely affects the life cycle of pathogens and enables plants to resist their attack by achieving better vigour and/or altering root physiology. This is evinced from the isolation of certain antagonistic organisms like actinomycetes and Pseudomonas species from vermicompost. Atiyeh., et al. [9] opined that vermicompost (VC) is a sustainable source of macro- and micro-nutrients, which enlivens the soil through partial substitution of the horticultural container media. Enhancement in plant growth after substitution of soils or greenhouse container media with conventional composts is attributed to modifications in soil structure, change in water availability, in- creased availability of macro- and micro - nutrients, stimulation of microbial activity, augmentation of the activities of critical enzymes, or production of plant growth - promoting substances by microorganisms through interactions with earthworms [10]. So enriching vermicompost with beneficial microbes like plant growth promoting bacteria and biocontrol organisms, will ensure better plant growth as well as suppression of soil - borne plant pathogens by modifying the physicochemical and microbiological characteristics of the plant growth medium beneficially [11]. In the present study among the different consortia of bioagents amended in VC, it was found that the consortia containing strain IISR 853, T. harzianum and biofertilizer organisms are more effective in enhancing the growth of the plants and also at par with other treatments in suppressing the infection by P. capsici. The study also revealed that sterile VC is comparatively more suitable for the proliferation of biocontrol agents and biofertilizer organisms than non-sterile VC, but for field applications it is not advisable to sterilize vermicompost as it denatures the enzymes which result in loss of the original qualities of vermicompost.

\section{Conclusion}

Suitability of vermicompost was evaluated as a base medium for the proliferation of promising biocontrol agents viz. P. aeruginosa (IISR 6, IISR 853), C. luteum (TC 10), T. harzianum, P. chlamydosporia and biofertilizer organisms viz. Azospirillum sp. ( $\mathrm{N}_{2}$ fixer), $P$. fluorescence ( $\mathrm{P}$ - solubilisers), potash mobilizers developed at IISR Calicut.

T. harzianum and A. lipoferum showed better growth and proliferation in sterile VC when compared with non sterile vermicompost. P. chlamidosporia showed decline in population in both sterile and non sterile vermicompost, but the decline was comparatively less in sterile VC when compared to non - sterile. The study clearly revealed that sterile VC is comparatively more suitable for the proliferation of biocontrol agents and biofertilizer organisms than non-sterile VC. But for field applications as soil amendment, it is not advisable to sterilize vermicompost due to the loss of enzymatic and microbial activities.

\section{Acknowledgement}

The authors are thankful to DDG (Hort) for suggestion and K Jayaraj for statistical analysis.

\section{Bibliography}

1. Anandaraj M., et al. "Role of Phytophthora capsici In The Slow Decline Disease Of Black Pepper". Journal of Plant Breeding and Crop Science (Suppl) 24 (1996): 166-170.

2. Sarma YR And Anandaraj M. "Phytophthora Foot Rot of Black Pepper". In Management of Threatening Diseases of National Importance. (Eds.) Agnihotri, V.P., Sarbhoy, A.K. And Singh, D.V. Malhotra Publishing House, New Delhi (1997): 237-248. 
3. Ramachandran N and Sarma YR. "Bioefficacy Of Systemic Fungicides Against Phytophthora Infection In Black Pepper (Piper Nigrum L.)". Journal of Plantation Crops 20 (1990): 79-84.

4. Diby Paul., et al. "Studies on the Suppressive Action of Fluorescent Pseudomonads on P. capsici, The Foot Rot Pathogen Of Black Pepper". In: Symposium On "Emerging Trends in Plant Disease Management" And Annual Meetings of India Phytopathological Society (2000).

5. Rajan PP., et al. "Management of foot rot disease of black pepper with Trichoderma spp". Indian Phytopathology 55.1 (2002): 34-38.

6. Kerry BR. "Ecological considerations for the use of the nematophagous fungus, Verticillium chlamydosporium, to control plant-parasitic nematodes". Canadian Journal of Botany 73 (1995): S65-S70.

7. Kumar R G and Singh D. "The potential of biological agents as Biopesticides". Farmer's Forum, 1.3 (2001): 22-26.

8. Chen W., et al. "Factors affecting suppression of Pythium damping-off in container media amended with composts". Phytopathology 77 (1987): 755-760.

9. Atiyeh., et al. "Effects of vermicompost and composts on plant growth in horticultural container media and soil". Pedobiologia 44.5 (2000): 579-590.

10. Marinari., et al. "Influence of organic and mineral fertilizers on soil biological and physical properties". Bioresource Technology 72 (2000): 9-17.

11. Kokalis-Burelle N., et al. "Plant Growth- Promoting Rhizobacteria As Transplant Amendments And Their Effects On Indigenous Rhizosphere Microorganisms". Applied Soil Ecology 31.12 (2006): 91-100.

Volume 3 Issue 10 October 2019

(c) All rights are reserved by Suseela Bhai R., et al. 